INTERNATIONAL JOURNAL
PHARMACEUTICAL SCIENCES
RESEARCH
RESTI

Received on 23 September, 2013; received in revised form, 29 October, 2013; accepted, 04 January, 2014; published 01 February, 2014

\title{
PROTEASOME INHIBITORS FOR USE IN MULTIPLE MYELOMA
}

\section{S. Jain* and N. Satija}

Fresenius Kabi Oncology Ltd., Echelon Institutional Area, Plot No. 11, Sector 32, Gurgaon - 122001, Haryana, India

Keywords:

Proteasome, Multiple Myeloma, Bortezomib, Carfilzomib

Correspondence to Author:

Smita Jain

Research Scientist-Intellectual Property Management, Fresenius

Kabi Oncology Ltd., Echelon

Institutional Area, Plot No. 11, Sector

32, Gurgaon - 122001, Haryana ,

India

E-mail: smita.jain@fresenius-kabi.com

\begin{abstract}
The approval of first-in-class proteasome inhibitor bortezomib in 2003, made possible the therapeutic validation of proteasome as a target for use in discovery and development of new treatment options in cancer, particularly haematological conditions like Multiple Myeloma. However, this breakthrough drug discovery suffered from a few limitations. As a result, the discovery of bortezomib not only introduced to the pharmaceutical research community a new area but also provided the impetus to work for a better future. The result was the recent approval of carfilzomib for use in relapsed and refractory multiple myeloma which revived the lagging area again and brought an upsurge in the area of research and development for second generation proteasome inhibitors directed towards this therapy. Here, we present a review on these second generation proteasome inhibitors currently in clinical or preclinical phase and try to assess the future for multiple myeloma therapy.
\end{abstract}

INTRODUCTION: The ubiquitin-proteasome pathway is a critical biological process which plays a central role in the regulation of several diverse cellular processes and thus inhibiting the ubiquitinproteasome pathway is an attractive target that would serve to provide us with molecular probes of major cellular networks as well as potential therapeutic agents for various human diseases.

Multiple myeloma therapy has been majorly benefitted from this approach as seen from the FDA approval of two such candidates, bortezomib and carfilzomib, for treatment of patients in the relapsed/refractory setting.

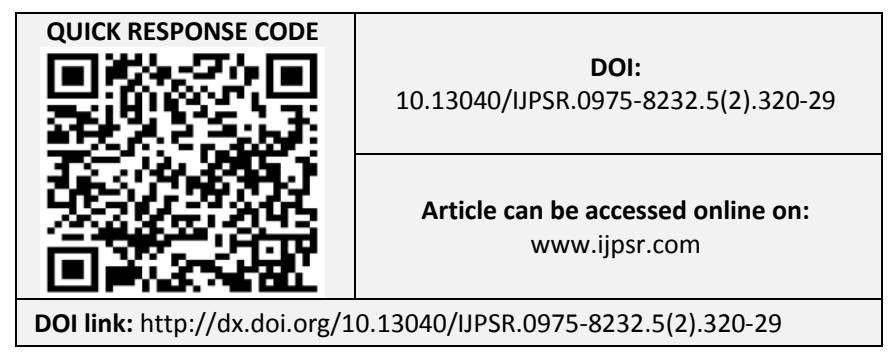

After the initial approval of bortezomib, in 2003 opened the horizons for clinical development of proteasome inhibitors for cancer therapeutics, the discovery area saw a declining interest due to the drug's limitations including some toxicity concerns and intravenous route of administration. However, the approval of carfilzomib once again brought an era of renaissance and the current pipeline of new proteasome inhibitors promises a brighter future for multiple myeloma therapy, both in frontline and relapsed/refractory settings.

Here, we have reviewed the second generation proteasome inhibitors which are in the clinical or preclinical phase at present and which may lead to some of the clinically successful candidates someday.

The Ubiquitin-Proteasome Pathway: The regulation and degradation of intracellular proteins is important for proper maintenance of the protein balance in the human body. 
In eukaryotic cells, there are two major mechanisms to keep a check on the protein cycle. These include the one controlled by proteolytic enzymes (proteases) present in cell organelles known as lysosomes and the other, the UbiquitinProteasome pathway which is the route of destruction for majority of proteins ${ }^{1}$.

The Ubiquitin-Proteasome pathway mediated degradation of proteins includes;

(a) Marking the protein by ligation of 76-amino acid ubiquitin polypeptide

(b) Identification of ubiquitinated proteins and proteolysis by a 26S-proteasome into smaller peptides.

The ubiquitination is a cascade reaction involving 3 different types of enzymes: E1, E2 and E3. E1 (Ubiquitin activating enzyme) activates the carboxyl group at the Gly-76 of ubiquitin polypeptide. Different combinations of E2 or E3 or both are responsible for the specificity of protein substrates.

The recognition process of ubiquitinated proteins by $26 \mathrm{~S}$ proteasome is followed by ATP-dependent unfolding and threading and finally indiscriminate unidirectional proteolysis. The uni-directionality of the process ensures that partially degraded proteins do not enter back ${ }^{2}$.

Other functions of the Ubiquitin-Proteasome pathway include various intracellular activities like major histo-compatibility complex (MHC) class I presentation, apoptosis, cell growth regulation, NF$\kappa \mathrm{B}$ activation, antigen processing, and transduction of pro-inflammatory signals ${ }^{1}$.

Proteasome as a Therapeutic target: The $26 \mathrm{~S}$ proteasome is composed of two basic units: a $20 \mathrm{~S}$ cylindrical protein complex forming the core flanked by two 19S protein caps on either ends. In another type of proteasome known as immuneproteasomes, the 20S core complex is flanked by two $11 \mathrm{~S}$ subunits ${ }^{3,4,5}$. The $19 \mathrm{~S}$ particle controls the recognition, deubiquitinylation and unfolding before its proteolysis by $20 \mathrm{~S}$ proteasome catalytic core $^{6}$.
The 20S proteasome consists of three major types of sites responsible for their respective activities. These include chymotrypsin-like protease (CT-L) activity, trypsin-like activity (T-L), and peptidylglutamyl peptide-hydrolyzing (PGPH) also known as caspase like activity. These particular subunits are responsible for hydrolysis of hydrophobic, basic and acidic amino acid residues respectively.

Two additional less characterized activities include BrAAP activity and SNAAP activity. These are responsible for cleavage of branched-chain amino acids and small neutral amino acids respectively ${ }^{6}$.

Analysis of mechanism of catalytic activity of $20 \mathrm{~S}$ proteasome has revealed importance of 'Thr-1' amino terminal residue as catalytic nucleophile in proteolysis ${ }^{6}$. Inhibitors of 20 S proteasome catalytic site including epoxyketones, peptide vinylsulfones (irreversible) and peptide aldehydes, boronic acid derivatives (reversible) target covalent binding of respective pharmacophore groups with the hydroxyl of Thr-1 which is responsible for their proteasome inhibiting activities, primarily at chymotrypsin-like activity sites.

Although the present list of proteasome inhibitors (Fig. 1) is only directed to target the $20 \mathrm{~S}$ proteasome subunit, future efforts may also focus on inhibition of the ubiquitination process to provide treatment options which are more substrate specific and for wider range of disorders.

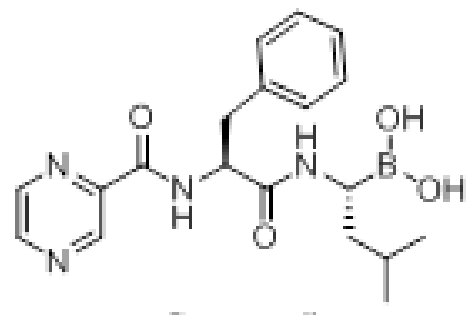

Bortezomib (Millenium Pharmaceuticals)

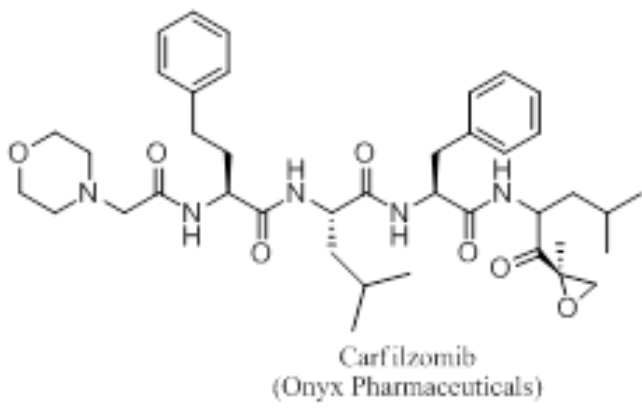




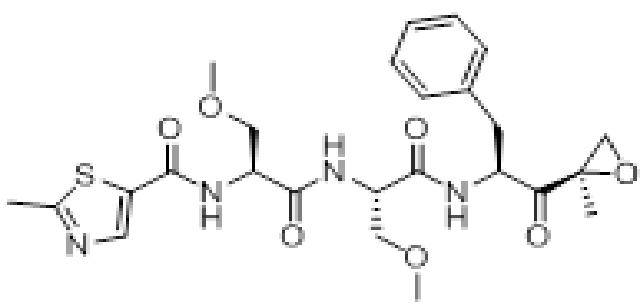

Oprozomib (Onyx Pharmaceuticals)
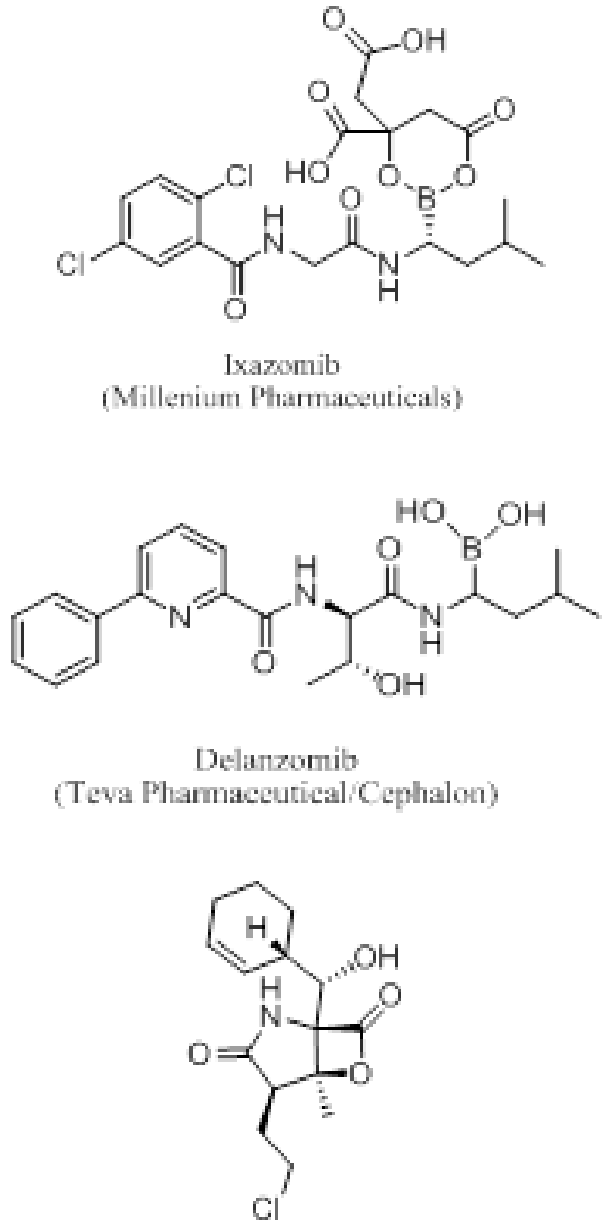

Marizomib

(Nereus Pharmaceuticals)

FIG. 1: BORTEZOMIB AND THE SECOND GENERATION PROTEASOME INHIBITORS IN MULTIPLE MYELOMA THERAPY

\section{Bortezomib: The First-in-Class Proteasome} Inhibitor: Bortezomib is a dipeptide boronic acid analogue and a reversible inhibitor of primarily the chymotrypsin-like activity of the 20S-proteasome. The drug is marketed under the name of Velcade by Millennium Pharmaceuticals for the treatment of patients suffering from multiple myeloma and for treatment of patients with mantle cell lymphoma who have received at least 1 prior therapy ${ }^{7}$.
The drug was a pioneer in its class and has gained an important position in the anticancer market as a standard of care for multiple myeloma cases in both relapsed/refractory and first-line settings ${ }^{8}$. But the therapy suffered from a few drawbacks which included a large proportion of myeloma patients being refractory and development of resistance to the treatment. In addition, a large group of patients receiving bortezomib therapy suffered from toxic and adverse reactions. Its side effects included peripheral neuropathy, haematological toxicity (reduced RBC and platelet count), asthenia, and other less common side effects like headache, pain in joints, reduced WBC count, arthralgia, myalgia etc ${ }^{9}$.

As explained before, boronic acid group of bortezomib form a complex with the $\beta-5$ subunit of the $20 \mathrm{~S}$ proteasome and inhibits the chymotrypsinlike activity which is responsible, primarily for its anticancer activity. Apart from these, bortezomib has also been observed to inhibit various additional biochemical pathways in preclinical studies. These include suppression of NF- $\kappa \mathrm{B}$. However, the exact pathway responsible for the clinical activity of bortezomib has not yet been assessed completely ${ }^{10}$.

Bortezomib has also been studied in other tumor malignancies like solid tumors as single agent where the results were not so promising but studies testing bortezomib in combination with conventional cancer therapies drugs like docetaxel ${ }^{11}$, doxorubicin ${ }^{12}$, melphalan ${ }^{13}$ or with radiation therapy ${ }^{14}$ or both $^{15}$ have shown encouraging results.

Overall, bortezomib presented great advancement to the field of proteasome-inhibiting anticancer agents for multiple myeloma but the toxicity and the development of resistance demanded for further studies and development of second generation proteasome inhibitors.

\section{Second Generation Proteasome Inhibitors:}

1. Carfilzomib: Carfilzomib (marketed under the tradename Kyprolis) is a selective, irreversible proteasome inhibitor approved recently on 20 July 2012 by USFDA for use in patients suffering from multiple myeloma who have received at least two prior therapies including bortezomib and an 
immunomodulatory agent and have demonstrated disease progression on or within 60 days of completion of the last therapy ${ }^{16}$. Chemically, carfilzomib is a tetrapeptide epoxyketone analogue of epoxomicin and eponemycin, a pair of related natural products that were isolated from Actinomycetes and identified as antitumor agents in animals ${ }^{17,18}$.

Epoxomycin primarily inhibits the chymotripsin-like activity of the proteasome but also inhibits, to a lesser extent, the other two proteolytic activities of the proteasome (trypsin-like and PGPH activity) 19. Eponemycin, however, along with its synthetic analogue dihydroeponemycin, inhibit both chymotrypsin-like and PGPH activity of proteasome at comparable rates 20.

These agents were shown to be extremely selective and potent proteasome inhibitors without exhibiting activity against any other cellular proteases by the laboratory of Craig Crews at Yale University. In addition to proteasome activity, epoxomicin also exhibits anti-inflammatory activity, presumably by inhibition of NF-kB activation $^{21}$.

The high selectivity of the Epoxomycin and derived epoxyketones for the proteasome activity was based on a unique mechanism comprising two-step reaction of the pharmacophore with both the hydroxyl and amino groups of the catalytic Thr residue. This involves the attack of the carbonyl group of the epoxyketone moiety by the catalytic hydroxyl, followed by the opening of the epoxy ring by the free $\alpha$-amino group to form a cyclical morpholino ring.

Crystal structure of the yeast 20S proteasome complexed with epoxomycin confirmed the formation of morpholino adduct between the epoxyketone pharmacophore and the active site $\mathrm{N}$ terminal Thr- ${ }^{22}$. The discovery chart of carfilzomib is illustrated in Fig. 2.
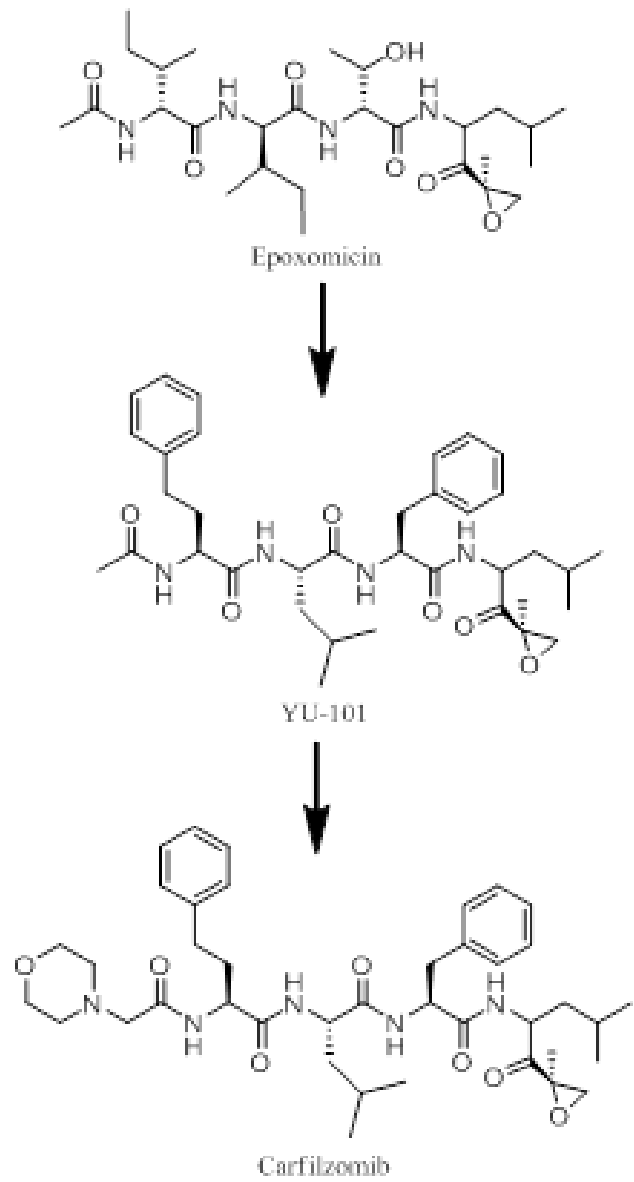

FIG. 2: DRUG DISCOVERY OF CARFILZOMIB

In order to obtain novel, more potent inhibitors with improved selectivity for each of the three major proteolytic activities of the proteasome and improved in vivo activity, the Crews laboratory synthesized a series of peptide $\alpha, \beta$-epoxyketones of varied length and amino acid sequence and characterized them for their ability to inhibit proteasomal enzymatic activity and cell growth ${ }^{23}$.

Most compounds selectively inhibited the chymotrypsin-like activity, while only weakly inhibiting the trypsin-like and PGPH activities. After optimization, one inhibitor, Ac-hFLFLepoxide (YU-101), was found to be more potent and selective for the inhibition of the chymotrypsin-like activity than others. This inhibitor also exhibiting strong in vivo antiinflammatory activity was licensed to Proteolix, Inc. Scientists at Proteolix later modified YU-101 to create carfilzomib ${ }^{23}$.

YU-101's in vitro and in vivo activities suggested that the molecule can be developed as both molecular probe and therapeutic agent. 
It was also supported by many reviewers that the molecule (YU-101) shows promising results and a great potential as a therapeutic agent and thus enforced the thought to develop the molecule for clinical uses ${ }^{24,25}$. The molecule although showed promising results in vitro and in vivo studies lacked on the water solubility front in order to be administered into the body. A polar or ionisable substitution could provide advantage with the solubility. Carfilzomib was the result of a substitution which enhanced the aqueous solubility of the parent molecule, YU-101 ${ }^{26}$.

The initial preclinical studies and clinical phase I and II studies were conducted by Proteolix Inc, which was taken over by Onyx in 2009. Onyx advanced the later stages of clinical trials of carfilzomib and finally succeeded with the drug's approval in $2012^{27}$.

Preclinical studies of carfilzomib in in vitro and in vivo xenograft models and in patient-derived models of myeloma demonstrated its apoptotic effects in a various tumor cell lines and supported its clinical evaluation for use in Multiple Myeloma 28,26

Apart from successful validation of carfilzomib for its indication relapsed/ refractory multiple myeloma 29,30 , several additional clinical phase studies are ongoing for evaluation of use of carfilzomib in combination with other chemotherapeutics active in multiple myeloma like lenalidomide and dexamethasone ${ }^{31-35}$. Clinical settings studying frontline use of carfilzomib at higher doses in cases where standard doses of carflzomib have become ineffective ${ }^{36}$ are also ongoing.

Further, carfilzomib was well tolerated with a few common observations like anemia, thrombocytopenia and leukemia etc. Peripheral neuropathy, a major concern with bortezomib therapy was not observed with cases on carfilzomib ${ }^{37}$.

2. Oprozomib (PR-047): Oprozomib (ONX 0912), another proteasome inhibitor being developed by Onyx, is considered the orally bioavailable analogue of carfilzomib ${ }^{38}$. ONX 0912, like carfilzomib targets primarily the chymotrypsin-like activity of the $20 \mathrm{~S}$ proteasome.
Oprozomib is advantageous to cancer patients as it provides comfort and ease of administration with oral dosage form as compared to injectables carfilzomib and bortezomib. Another advantage offered by the different dosage form of this inhibitor of the class is the flexibility of dosage adjustment and in combinations with other available anticancer agents like Dexamethasone and Lenalidomide in myeloma therapy ${ }^{39}$. The potential drug molecule presented positive broad therapeutic window and anticancer activity in myeloma cells ${ }^{40}$.

Currently, there three clinical studies active for this molecule for use in Multiple Myeloma in single line therapy ${ }^{41}$ and in combination with drugs like lenalidomide and dexamethasone 42,43 and one in advanced solid tumors ${ }^{44}$.

\section{Marizomib (NPI-0052; salinosporamide} A): Marizomib, like carfilzomib predecessor epoxomicin, is a natural nonpeptide irreversible proteasome inhibitor, derived from marine actinomycete genus Salinospora. Structurally it is a $\beta$ lactone- $\gamma$-lactam, distinct from boronic acid and epoxyketone class of proteasome inhibitors. The discovery of in vitro anticancer activities of this natural compound inspired synthesis of varied structural analogues, but of all, the molecule itself (Salinosporamide A) was considered the worthiest to have entered clinical trials 45

The molecule NPI-0052 is orally bioavailable and distinct from bortezomib in its structure, mechanism of action and its activity/toxicity profile. Both in vitro / in vivo mechanistic studies confirm that the molecule inhibits chymotrypsin like activity of proteasome among other activities at a smaller concentration than bortezomib, inhibit $\mathrm{NF}-\kappa \mathrm{B}$ at a greater potency, is free from bortezomib associated toxicities and active against bortezomib resistant /refractory multiple myeloma. 
There are also evidences in support of the role of distinct caspase-8 and caspase-9mediated cell death signaling pathway in anti-myeloma cell activity of marizomib which is also thought to be the reason behind its synergistic activity in combination with bortezomib ${ }^{46}$.

The preclinical studies characterize the beneficial biological profile of the molecule very well and thus provide rationale for its clinical development 47, 48. The clinical studies for marizomib are being conducted by Triphase Research and Development I Corporation. Currently, Phase I clinical trials comprising biweekly administration of intravenous marizomib are ongoing for use in multiple myeloma patients who have been refractory to carfilzomib treatment ${ }^{49}$.

Other recently completed Phase 1 clinical studies include use of marizomib in combination with voriconazole in conditions like lung cancer, pancreatic cancer, myeloma, lymphoma and multiple myeloma ${ }^{50}$ and in advanced malignancies like solid tumors, lymphomas, leukemias and myelomas ${ }^{51}$ or refractory solid tumors or lymphomas ${ }^{52}$ as single therapy.

4. Ixazomib (MLN9708): It is the first oral reversible proteasome inhibitor to have entered clinical trials for treatment for relapsed and/or refractory myeloma, including myeloma that has stopped responding to Velcade ${ }^{\circledR}$ (bortezomib). The newly developed therapy offers advantage of fewer, less serious side effects with the comfort of oral administration and is free from major concerns like peripheral neuropathy common with bortezomib.

Another improvement in this molecule over bortezomib is its better pharmacokinetic profile. MLN9708 (ixazomib) is a citrate ester of boronic acid which is hydrolysed rapidly to release the biologically active MLN2238 (boronic acid) in aqueous environment. MLN2238 is dissociated rapidly from its binding site at $20 \mathrm{~S}$ proteasome in red blood cells which enables its fast biodistribution and reach a higher tumor to blood ratio as compared to other proteasome inhibitors which either irreversibly bind to proteasome (carfilzomib, oprozomib and marizomib) or dissociate slowly (reversible inhibitors like bortezomib and delanzomib). Studies of MLN9708 in preclinical xenograft models established a direct correlation between its pharmacodynamics and antitumor activity and supported its clinical development for both solid tumors and haematological tumors ${ }^{53}$.

The studies further demonstrate that the molecule has better efficacy, superior bioavailability, flexibility of dosage form, and improved overall survival as compared with bortezomib ${ }^{54}$. Similar in vitro and in vivo studies for ixazomib were conducted using animal and human xenograft mouse models which also supported clinical development of the molecule for haematological malignancies especially, Multiple Myeloma ${ }^{54,55}$.

Currently, two phase I trials with single agent ixazomib for use in multiple myeloma are ongoing 56,57 . The two ongoing studies evaluate the weekly and twice-weekly oral dosage regimens for adult patients with relapsed and refractory multiple myeloma. Preliminary results show that both regimens had visible anti-myeloma effects and were tolerated well without any serious toxicity concerns. However, it was also suggested that weekly ixazomib dosing may be better tolerated than twice-weekly dosing ${ }^{58-60}$.

In addition to ixazomib as single clinical agent, there are running various parallel clinical studies where ixazomib is administered in combination with other antitumor agents. Two Phase I/II trials comprising weekly ixazomib ${ }^{61}$ and twiceweekly ixazomib ${ }^{62}$ is being evaluated in combination with standard dose Revlimid and dexamethasone in patients with newly diagnosed myeloma. Few phase 3 studies for Revlimid $^{\circledR}$ and dexamethasone combination with ixazomib are also ongoing ${ }^{63,64}$. 
The purpose of these studies include evaluation of MLN9708 in combination with lenalidomide and dexamethasone in newly diagnosed multiple myeloma and relapsed and/or refractory multiple myeloma respectively. Another Phase 1 pharmacokinetic study is ongoing for investigation of oral MLN9708 plus Lenalidomide and Dexamethasone in adult asian patients with relapsed and/or refractory multiple myeloma ${ }^{65}$.

Other combination studies include phase I/II study of oral MLN9708 in combination with melphalan and prednisone in patients with newly diagnosed multiple myeloma 66 and Phase I pharmacokinetics study of oral MLN9708 plus dexamethasone in Relapsed/Refractory Multiple Myeloma patients ${ }^{67}$. Additional clinical trials of ixazomib for conditions like Relapsed or Refractory Light Chain Amyloidosis, Nonhematologic Malignancies and Lymphomas alone or in combinations are also being explored ${ }^{68-71}$.

5. Delanzomib (CEP-18770): Another second generation proteasome inhibitor synthesized as a result of the ongoing quest for a better second generation proteasome inhibitor is delanzomib. CEP-18770 like bortezomib, is a reversible boronate exhibiting selective chymotrypsin-like activity and additional suppression of NF- $\kappa \mathrm{B}$ mediated signaling pathways and transcriptional targets of NF$\mathrm{Kb}{ }^{70}$. Delanzomib also presents a flexibility of dosage form i.e. it can be formulated as oral/intravenous agent. In preclinical studies, the molecule in single agent therapy has shown results which display a better antitumor activity in comparison with bortezomib as studied from in vitro and in vivo experiments ${ }^{72,73}$. Use of delanzomib in combination with other anticancer agents for treatment of myeloma malignancies have also been studied in preclinical models. In a study, it was examined that the molecule can be used to enhance anti-myeloma effects of melphalan or bortezomib as an orally bioavailable agent ${ }^{74}$.
Another similar study evaluated the use of novel molecule in combination with dexamethasone and lenalidomide. The study showed significant synergistic results in multiple myeloma tumor settings and could overcome bortezomib resistance ${ }^{75}$. These impressive study results provided support for clinical evaluation of this new proteasome inhibitor, CEP-18770, as single agent and in combination regimens for patients with progressive or resistant/ relapsed multiple myleoma.

Phase I/II clinical studies of the molecule as single agent have been initiated in patients with relapsed and refractory multiple myeloma ${ }^{76}$. Combination studies of CEP18770 with lenalidomide and dexamethasone in relapsed or refractory multiple myelomas are also ongoing ${ }^{77}$.

CONCLUSION: The drug discovery of bortezomib and its successful advent into the pharmaceutical market has introduced to the research community, a new biological drug target for development of novel anticancer drugs. However, the molecule suffered from many serious drawbacks and toxicity reasons. Thus in order to maintain the anti-myeloma therapy options available to the practitioners in clinic, there exist a need to back up this research field with newer and better proteasome inhibitors having application in anti-myeloma therapy.

To answer this concern, there has been a lot of surveillance in the area which has resulted in a number of potential molecules entering clinical trials. These newer alternatives provide advantages of limited toxicity, better activity, activity against resistant multiple myeloma cancers and the flexibility of oral formulation (except carfilzomib). One such successful candidate to reach the patient's bedside is carfilzomib which was approved recently in 2012. Although, these agents have proved to be better in single line studies, many clinical trials are running which are directed towards evaluation of these in multiple agent therapy. Therefore, it is certain that if the field of proteasome inhibitors is analysed more closely, there awaits, definitely, a future better than today for the myeloma patients. 


\section{REFERENCES:}

1. Myung J, Kim KB and Crews CM: The UbiquitinProteasome Pathway and Proteasome Inhibitors. Medicinal Research Reviews 2001; 21(4):245-273.

2. Ciechanover $A$ and Schwartz AL: The ubiquitinproteasome pathway: The complexity and myriad functions of proteins death. Proceedings of the National Academy of Sciences USA 1998; 95(6):2727-2730.

3. Löwe J, Stock D, Jap B, Zwickl P, Baumeister W and Huber R: Crystal structure of the 20S proteasome from the archaeon T. acidophilum at $3.4 \AA$ resolution. Science 1995; 268:533-539.

4. Groll M, Ditzel L, Lowe J, Stock D, Bochtler M, Bartunik HD and Huber R: Structure of 20S proteasome from yeast at $2.4 \AA$ resolution. Nature (London) 1997; 386:463-471.

5. Kopp F, Hendil KB, Dahlmann B, Kristensen P, Sobek A and Uerkvitz W: Subunit arrangement in the human 20S proteasome. Proceedings of the National Academy of Sciences USA 1997; 94(7): 2939-2944.

6. Almond JB and Cohen GM: The proteasome: a novel target for cancer chemotherapy. Leukemia 2002; 16(4):433-443.

7. USFDA. Velcade (Bortezomib) for Injection. http://www.accessdata.fda.gov/drugsatfda_docs/label/2008 /021602s015lbl.pdf (Last Accessed: Sep 22, 2013)

8. Twombly R: First Proteasome Inhibitor Approved for Multiple Myeloma. Journal of the National Cancer Institute 2003; 95(12):845.

9. Chen D, Frezza M, Schmitt S, Kanwar J and Dou QP: Bortezomib as the first proteasome inhibitor anticancer drug: current status and future perspectives. Current Cancer Drug Targets 2011; 11(3):239-253.

10. Dick LR and Fleming PE: Building on bortezomib: second-generation proteasome inhibitors as anti-cancer therapy. Drug Discovery Today 2010; 15(5/6):243-249.

11. Messersmith WA, Baker SD, Lassiter L, Sullivan RA, Dinh K, Almuete VI, Wright JJ, Donehower RC, Carducci MA and Armstrong D: Phase I trial of bortezomib in combination with docetaxel in patients with advanced solid tumors. Clinical Cancer Research 2006; 12(4):1270-1275.

12. Orlowski RZ, Voorhees PM, Garcia RA, Hall MD, Kudrik FJ, Allred T, Johri AR, Jones PE, Ivanova A, Van Deventer HW, Gabriel DA, Shea TC, Mitchell BS, Adams J, Esseltine DL, Trehu EG, Green M, Lehman MJ, Natoli S, Collins JM, Lindley CM and Dees EC: Phase 1 trial of the proteasome inhibitor bortezomib and pegylated liposomal doxorubicin in patients with advanced hematologic malignancies. Blood 2005; 105(8):3058-3065.

13. Berenson JR, Yang HH, Sadler K, Jarutirasarn SG, Vescio RA, Mapes R, Purner M, Lee SP, Wilson J, Morrison B, Adams J, Schenkein D and Swift R: Phase I/II trial assessing bortezomib and melphalan combination therapy for the treatment of patients with relapsed or refractory multiple myeloma. Journal of Clinical Oncology 2006; 24(6):937-944

14. Russo SM, Tepper JE, Baldwin AS Jr, Liu R, Adams J, Elliott $P$ and Cusack JC Jr.: Enhancement of radiosensitivity by proteasome inhibition: implications for a role of NF-kappaB. International Journal Radiation Oncology Biology Physics 2001; 50(1):183-193.

15. Edelman MJ: The potential role of bortezomib in combination with chemotherapy and radiation in nonsmall-cell lung cancer. Clinical Lung Cancer 2005; 7 Suppl 2:S64-66.

16. USFDA. FDA approves Kyprolis for some patients with multiple myeloma. http://www.fda.gov/newsevents/newsroom/pressannounce ments/ucm312920.htm (Last Accessed: Sep 22, 2013)

17. Hanada M, Sugawara K, Kaneta K, Toda S, Nishiyama Y, Tomita K, Yamamoto H, Konishi $\mathrm{M}$ and Oki T: Epoxomicin, a new antitumor agent of microbial origin. Journal of Antibiotics (Tokyo) 1992; 45:1746-1752.

18. Sugawara K, Hatori M, Nishiyama Y, Tomita K, Kamei H, Konishi $\mathrm{M}$ and Oki T: Eponemycin, A New Antibiotic Active Against B16 Melanoma. Production, Isolation, Structure and Biological Activity. Journal of Antibiotics (Tokyo) 1990; 43:8-18.

19. Sin N, Kim KB, Elofsson M, Meng L, Auth H, Kwok BH and Crews CM: Total synthesis of the potent proteasome inhibitor epoxomicin: a useful tool for understanding proteasome biology. Bioorganic and Medicinal Chemistry Letters 1999; 9:2283-2288.

20. Meng L, Kwok BH, Sin N and Crews CM: Eponemycin Exerts Its Antitumor Effect through the Inhibition of Proteasome Function. Cancer Research 1999; 59:27982801.

21. Meng L, Mohan R, Kwok BH, Elofsson M, Sin N and Crews CM: Epoxomicin, a potent and selective proteasome inhibitor, exhibits in vivo antiinflammatory activity. Proceedings of the National Academy of Sciences USA 1999; 96:10403-10408.

22. Groll M, Kim KB, Kairies N, Huber R and Crews CM: Crystal structure of epoxomicin: $20 \mathrm{~S}$ proteasome reveals a molecular basis of $\alpha, \beta$-epoxyketone proteasome inhibitors. Journal of American Chemical Society 2000; 122:12371238 .

23. Elofsson M, Splittgerber U, Myung J, Mohan R and Crews CM: Towards subunit-specific proteasome inhibitors: synthesis and evaluation of peptide $\alpha, \beta$-epoxyketones. Chemistry and Biology 1999; 6(1):811-822.

24. Adams J: Proteasome Inhibitors as therapeutic agents. Expert Opinion on Therapeutic Patents 2003; 13(1):45-57.

25. Delcros JG, Floc'h MB, Prigent $\mathrm{C}$ and Arlot-Bonnemains Y: Proteasome Inhibitors as Therapeutic Agents: Current and Future Strategies. Current Medicinal Chemistry 2003; 10:479-503.

26. Demo SD, Kirk CJ, Aujay MA, Buchholz TJ, Dajee M, Ho MN, Jiang J, Laidig GJ, Lewis ER, Parlati F, Shenk KD, Smyth MS, Sun CM, Vallone MK, Woo TM, Molineaux CJ and Bennett MK: Antitumor Activity of PR-171, a Novel Irreversible Inhibitor of the Proteasome. Cancer Research 2007; 67(13):6383-6391.

27. Halford B: Carfilzomib: From Discovery to Drug. Chemistry \& Engineering News 2012; 90(35):34-35. Online available from: http://cen.acs.org/articles/90/i35/Carfilzomib-DiscoveryDrug.html (Last Accessed: 26 August 2013)

28. Kuhn DJ, Chen Q, Voorhees PM, Strader JS, Shenk KD, Sun CM, Demo SD, Bennett MK, van Leeuwen FWB, Chanan-Khan AA and Orlowski RZ: Potent activity of carfilzomib, a novel, irreversible inhibitor of the ubiquitinproteasome pathway, against preclinical models of multiple myeloma. Blood 2007; 110:3281-3290.

29. Siegel DS, Martin T, Wang M, Vij R, Jakubowiak AJ, Lonial S, Trudel S, Kukreti V, Bahlis N, Alsina M, Chanan-Khan A, Buadi F, Reu FJ, Somlo G, Zonder J, Song K, Stewart AK, Stadtmauer E, Kunkel L, Wear S, Wong AF, Orlowski RZ and Jagannath S: A phase 2 study of single-agent carfilzomib (PX-171-003-A1) in patients with relapsed and refractory multiple myeloma. Blood 2012; 120:2817-2825.

30. Clinicaltrials.gov. A Study of carfilzomib vs Best Supportive Care in Subjects with Relapsed and Refractory Multiple Myeloma

(FOCUS) 
http://clinicaltrials.gov/show/NCT01302392.

(Last Accessed: Sep 22, 2013)

31. Clinicaltrials.gov. Phase 3 Study Comparing Carfilzomib, Lenalidomide, and Dexamethasone (CRd) vs Lenalidomide and Dexamethasone (Rd) in Subjects with Relapsed Multiple Myeloma. http://clinicaltrials.gov/ show/NCT01080391 (Last Accessed: Sep 22, 2013)

32. Clinicaltrials.gov. Cyclophosphamide, Carfilzomib, Thalidomide, and Dexamethasone in Treating Patients With Newly Diagnosed Active Multiple Myeloma. http://clinicaltrials.gov/show/NCT01057225 (Last Accessed: Sep 22, 2013)

33. Clinicaltrials.gov. Phase 3 Study With Carfilzomib and Dexamethasone Versus Velcade and Dexamethasone for relapsed Multiple Myeloma Patients (ENDEAVOR). http://clinicaltrials.gov/ct2/show/NCT01568866 (Last Accessed: Sep 22, 2013)

34. Clinicaltrials.gov. Phase 3 Study of Carfilzomib, Melphalan, Prednisone vs Bortezomib, Melphalan, Prednisone in Newly Diagnosed Multiple Myeloma (CLARION)

http://clinicaltrials.gov/ct2/show/NCT01818752 (Last Accessed: Sep 22, 2013)

35. Clinicaltrials.gov. Bortezomib or Carfilzomib With Lenalidomide and Dexamethasone in Treating Patients With Newly Diagnosed Multiple Myeloma. http://clinicaltrials.gov/ct2/show/NCT01863550 (Last Accessed: Sep 22, 2013)

36. Clinicaltrials.gov. Study of High Dose Carfilzomib in Multiple Myeloma Patients Who Have Progressed On Standard Dose Carfilzomib. http://clinicaltrials.gov/ct2/show/NCT01775553 (Last Accessed: Sep 22, 2013)

37. Adib R, Patel $\mathrm{K}$ and Abdelghany S: Carfilzomib: A second-generation proteasome inhibitor for the treatment of muitipie myeloma. Formulary 2012; 47:282-308.

38. Onyx Pharmaceuticals. Clinical Development. Oprozomib. Source: http://www.onyx.com/clinicaldevelopment/oprozomib (Last Accessed: Sep 22, 2013)

39. Zhou HJ, Aujay MA, Bennett MK, Dajee M, Demo SD, Fang Y, Ho MN, Jiang J, Kirk CJ, Laidig GJ, Lewis ER, Lu Y, Muchamuel T, Parlati F, Ring E, Shenk KD, Shields J, Shwonek PJ, Stanton T, Sun CM, Sylvain C, Woo TM and Yang J: Design and synthesis of an orally bioavailable and selective peptide epoxyketone proteasome inhibitor (PR-047). Journal of Medicinal Chemistry 2009; 52(9):3028-3038.

40. Chauhan D, Singh AV, Aujay M, Kirk CJ, Bandi M, Ciccarelli B, Raje N, Richardson P Anderson and Kenneth C: A novel orally active proteasome inhibitor ONX 0912 triggers in vitro and in vivo cytotoxicity in multiple myeloma. Blood 2010; 116(23): 4906-4915.

41. Clinicaltrials.gov. Open-label Study of the Safety and Activity of Oprozomib in Patients With Hematologic Malignancies.

http://clinicaltrials.gov/ct2/show/NCT01416428. (Last Accessed: Sep 22, 2013)

42. Clinicaltrials.gov. Phase $1 \mathrm{~b} / 2$, Multicenter, Open-label Study of Oprozomib and Dexamethasone in Patients With Relapsed and/or Refractory Multiple Myeloma. http://clinicaltrials.gov/ct2/show/NCT01832727. (Last Accessed: Sep 22, 2013)

43. Clinicaltrials.gov. Phase $1 \mathrm{~b} / 2$, Multicenter, Open-label Study of Oprozomib, Lenalidomide, and Dexamethasone in Patients With Newly Diagnosed Multiple Myeloma. http://clinicaltrials.gov/ct2/show/NCT01881789 (Last Accessed: Sep 22, 2013).
44. Clinicaltrials.gov. Phase 1 Study of ONX 0912 Administered Orally in Patients With Advanced Refractory or Recurrent Solid Tumors. http://clinicaltrials.gov/ct2/show/NCT01129349 (Last Accessed: Sep 22, 2013)

45. Feling RH, Buchanan GO, Mincer TJ, Kauffman CA, Jensen PR and Fenical W: Salinosporamide A: a highly cytotoxic proteasome inhibitor from a novel microbial source, a marine bacterium of the new genus salinospora. Angewandte Chemie International Edition 2003; 42(3):355-357.

46. Chauhan D, Catley L, Li G, Podar K, Hideshima T, Velankar M, Mitsiades C, Mitsiades N, Yasui H, Letai A, Ovaa H, Berkers C, Nicholson B, Chao TH, Neuteboom ST, Richardson P, Palladino MA and Anderson KC: A novel orally active proteasome inhibitor induces apoptosis in multiple myeloma cells with mechanisms distinct from Bortezomib. Cancer Cell 2005; 8(5):407-419.

47. Singh AV, Palladino MA, Lloyd GK, Potts BC, Chauhan $\mathrm{D}$ and Anderson KC: Pharmacodynamic and efficacy studies of the novel proteasome inhibitor NPI-0052 (marizomib) in a human plasmacytoma xenograft murine model. British Journal of Haematology 2010; 149:550559.

48. Potts BC, Albitar MX, Anderson KC, Baritaki S, Berkers C, Bonavida B, Chandra J, Chauhan D, Cusack JC Jr, Fenical W, Ghobrial IM, Groll M, Jensen PR, Lam KS, Lloyd GK, McBride W, McConkey DJ, Miller CP, Neuteboom STC, Oki Y, Ovaa H, Pajonk F, Richardson PG, Roccaro AM, Sloss CM, Spear MA, Valashi E, Younes A and Palladino MA: Marizomib, a Proteasome Inhibitor for All Seasons: Preclinical Profile and a Framework for Clinical Trials. Current Cancer Drug Targets 2011; 11(3):254-284.

49. Clinicaltrials.gov. Phase 1 Clinical Trial of NPI-0052 in Patients With Relapsed or Relapsed/Refractory Multiple Myeloma. http://clinicaltrials.gov/ct2/show/NCT00461045 (Last Accessed: Sep 22, 2013)

50. Clinicaltrials.gov. Proteasome Inhibitor NPI-0052 and Vorinostat in Patients With Non-small Cell Lung Cancer, Pancreatic Cancer, Melanoma or Lymphoma. http://clinicaltrials.gov/ct2/show/NCT00667082 (Last Accessed: Sep 22, 2013)

51. Clinicaltrials.gov. Phase 1 Clinical Trial in Patients With Advanced Malignancies. http://clinicaltrials.gov/ct2/show/NCT00629473 (Last Accessed: Sep 22, 2013)

52. Clinicaltrials.gov. Phase 1 Clinical Trial of NPI-0052 in Patients With Advanced Solid Tumor Malignancies or Refractory Lymphoma. http://clinicaltrials.gov/ct2/ show/NCT00396864 (Last Accessed: Sep 22, 2013)

53. Kupperman E, Lee EC, Cao Y, Bannerman B, Fitzgerald M, Berger A, Yu J, Yang Y, Hales P, Bruzzese F, Liu J, Blank J, Garcia K, Tsu C, Dick L, Fleming P, Yu L, Manfredi M, Rolfe $\mathrm{M}$ and Bolen $\mathrm{J}$ : Evaluation of the proteasome inhibitor MLN9708 in preclinical models of human cancer. Cancer Research 2010; 70(5):1970-1980.

54. Chauhan D, Tian Z, Zhou B, Kuhn D, Orlowski R, Raje N, Richardson $\mathrm{P}$ and Anderson KC: In Vitro and In Vivo Selective Antitumor Activity of a Novel Orally Bioavailable Proteasome Inhibitor MLN9708 against Multiple Myeloma Cells. Clinical Cancer Research 2011; 17(16):5311-5321.

55. Lee EC, Fitzgerald M, Bannerman B, Donelan J, Bano K, Terkelsen J, Bradley DP, Subakan O, Silva MD, Liu R, Pickard M, Li Z, Tayber O, Li P, Hales P, Carsillo M, Neppalli VT, Berger AJ, Kupperman E, Manfredi M, Bolen JB, Van Ness B and Janz S: Antitumor Activity 
of the Investigational Proteasome Inhibitor MLN9708 in Mouse Models of B-cell and Plasma Cell Malignancies. Clinical Cancer Research 2011; 17(23):1-11.

56. Clinicaltrials.gov. Study Evaluating the Safety and Tolerability of Weekly Dosing of Oral MLN9708 in Adult Patients with Relapsed and Refractory Multiple Myeloma. http://clinicaltrials.gov/ct2/show/NCT00963820 (Last Accessed: Sep 22, 2013)

57. Clinicaltrials.gov. Study of Oral MLN9708 in Adult Patients With Relapsed and/or Refractory Multiple Myeloma. http://clinicaltrials.gov/ct2/show/NCT00932698 (Last Accessed: Sep 22, 2013)

58. Kumar S, Bensinger WI, Reeder CB, Zimmerman TM, Berenson JR, Berg D, Liu G, Gupta N, Bacco AD, Hui A$\mathrm{M}$ and Niesvizky R: Weekly dosing of the investigational oral proteasome inhibitor MLN9708 in patients with relapsed and/or refractory multiple myeloma: Results from a phase 1 dose-escalation study. Blood 2011; 118(21): Abstract 816.

59. Richardson PG, Baz R, Wang L, Jakubowiak AJ, Berg D, Liu G, Gupta G, Bacco AD, Hui A-M and Lonial S: Investigational agent MLN9708, an oral proteasome inhibitor, in patients (pts) with relapsed and/or refractory multiple myeloma (MM): Results from the expansion cohorts of a phase 1 dose-escalation study. Blood 2011; 118(21): Abstract 301.

60. Takeda Pharmaceutical Company Limited. ASCO Presentation Highlights Results of Single Agent Oral MLN9708 in Heavily Pretreated Patients with Relapsed and/or Refractory Multiple Myeloma. http://www.takeda.com/news/2013/20130604_5808.html (Last Accessed: 22 Sep 2013)

61. Clinicaltrials.gov. A Study of MLN9708 Administered in Combination With Lenalidomide and Low-Dose Dexamethasone in Patients With Newly Diagnosed Multiple Myeloma. http://clinicaltrials.gov/ct2/ show/NCT01217957 (Last Accessed: Sep 22, 2013)

62. Clinicaltrials.gov. Study of Oral MLN9708 in Combination With Lenalidomide and Dexamethasone in Patients With Newly Diagnosed Multiple Myeloma. http://clinicaltrials.gov/ct2/show/NCT01383928 (Last Accessed: Sep 22, 2013)

63. Clinicaltrials.gov. MLN9708 Plus Lenalidomide and Dexamethasone versus Placebo Plus Lenalidomide and Dexamethasone in Adult Patients with Newly Diagnosed Multiple Myeloma. http://clinicaltrials.gov/ct2/ show/NCT01850524 (Last Accessed: Sep 22, 2013)

64. Clinicaltrials.gov. A Phase 3 Study Comparing Oral MLN9708 Plus Lenalidomide and Dexamethasone Versus Placebo Plus Lenalidomide and Dexamethasone in Adult Patients With Relapsed and/or Refractory Multiple Myeloma. http://clinicaltrials.gov/ct2/show/NCT01564537 (Last Accessed: Sep 22, 2013)

65. Clinicaltrials.gov. Phase 1 Pharmacokinetic Study of Oral MLN9708 Plus Lenalidomide and Dexamethasone in Adult Asian Patients with Relapsed and/or Refractory Multiple Myeloma. http://clinicaltrials.gov/ ct2/show/NCT01645930. NCT01645930 (Last Accessed: Sep 22, 2013)

66. Clinicaltrials.gov. Study of Oral MLN9708 in Combination With Melphalan and Prednisone in Patients
With Newly Diagnosed Multiple Myeloma. http://clinicaltrials.gov/ct2/show/NCT01335685 (Last Accessed: Sep 22, 2013)

67. Clinicaltrials.gov. Pharmacokinetics Study of Oral MLN9708 Plus Dexamethasone in Relapsed/Refractory Multiple Myeloma Patients. http://clinicaltrials.gov/ct2/ show/NCT01830816 (Last Accessed: Sep 22, 2013)

68. Clinicaltrials.gov. A Study of MLN9708 in Adult Patients with Lymphoma. http://clinicaltrials.gov/ct2/ show/NCT00893464 (Last Accessed: Sep 22, 2013)

69. Clinicaltrials.gov. A Phase 1 Study of MLN9708 in Adult Patients With Advanced Nonhematologic Malignancies. http://clinicaltrials.gov/ct2/show/NCT00830869 (Last Accessed: Sep 22, 2013)

70. Clinicaltrials.gov. Phase 2 Study of Oral MLN9708 in Adult Patients with Relapsed and/or Refractory Follicular Lymphoma.

http://clinicaltrials.gov/ct2/show/NCT01939899

(Last Accessed: Sep 22, 2013)

71. Clinicaltrials.gov. Phase 1 Pharmacokinetics Study of Oral MLN9708 in Patients With Advanced Nonhematologic Malignancies or Lymphoma. http://clinicaltrials.gov/ct2/ show/NCT01454076 (Last Accessed: Sep 22, 2013)

72. Dorsey BD, Iqbal M, Chatterjee S, Menta E, Bernardini R, Bernareggi A, Cassara PG, Arasmo DG, Ferretti E, De Munari S, Olivia A, Pezzoni G, Allievi C, Strepponi I, Ruggeri B, Ator MA, Williams $\mathrm{M}$ and Mallamo JP: Discovery of a potent, selective, and orally active proteasome inhibitor for the treatment of cancer. Journal of Medicinal Chemistry 2008; 51:1068-1072.

73. Piva R, Ruggeri B, Williams M, Costa G, Tamagno I, Ferrero D, Giai V, Coscia M, Peola S, Massaia M, Pezzoni G, Allievi C, Pescalli N, Cassin M, di Giovine S, Nicoli P, de Feudis P, Strepponi I, Roato I, Ferracini R, Bussolati B, Camussi G, Jones-Bolin S, Hunter K, Zhao H, Neri A, Palumbo A, Berkers C, Ovaa $\mathrm{H}$, Bernareggi A and Inghirami G: CEP-18770: a novel orally-active proteasome inhibitor with a tumor-selective pharmacological profile competitive with bortezomib. Blood 2008; 111: 27652775.

74. Sanchez E, Li M, Steinberg JA, Wang C, Shen J, Bonavida $\mathrm{B}, \mathrm{Li} \mathrm{ZW}$, Chen $\mathrm{H}$ and Berenson JR: The proteasome inhibitor CEP-18770 enhances the anti-myeloma activity of bortezomib and melphalan. British Journal of Haematology 2010; 148(4):569-581.

75. Sanchez E, Li M, Li J, Wang C, Chen H, Jones-Bolin S, Hunter K, Ruggeri B and Berenson JR: CEP-18770 (delanzomib) in combination with dexamethasone and lenalidomide inhibits the growth of multiple myeloma. Leukemia Research 2012; 36(11):1422-1427.

76. Clinicaltrials.gov. Study to Determine the Maximum Tolerated Dose and Evaluate the Efficacy and Safety of CEP-18770 in Patients with Relapsed Multiple Myeloma Refractory to the Most Recent Therapy. http://clinicaltrials.gov/show/NCT01023880 (Last Accessed: Sep 22, 2013)

77. Clinicaltrials.gov. CEP-18770 in Combination with Lenalidomide and Dexamethasone in Relapsed or Refractory Multiple Myeloma. http://clinicaltrials.gov /show/NCT01348919 (Last Accessed: Sep 22, 2013)

\section{How to cite this article:}

Jain S and Satija N: Proteasome inhibitors for use in Multiple Myeloma. Int J Pharm Sci Res 2014; 5(2): 320-29.doi: 10.13040/IJPSR. 0975-8232.5(2).320-29

All $\odot 2013$ are reserved by International Journal of Pharmaceutical Sciences and Research. This Journal licensed under a Creative Commons Attribution-NonCommercial-ShareAlike 3.0 Unported License. This article can be downloaded to ANDROID OS based mobile. Scan QR Code using Code/Bar Scanner from your mobile. (Scanners are available on Google Playstore) 